\title{
The Impact of digital technology on e-commerce development in Russian Federation
}

\author{
Elena Lobacheva ${ }^{1}$, Natalia Yadova $^{2}$ \\ ${ }^{1}$ Head of department «Economy and Business», professor, Doctor of Economical Sc., Bauman \\ University, Moscow; \\ ${ }^{2}$ Associate professor, PhD, department «Economy and Business», Bauman University, Moscow.
}

\begin{abstract}
The article is devoted to the problem of development and influence of digital technologies on e-Commerce enterprises. The types and forms of digital technologies used in this field are studied the characteristics and features of modern e-Commerce in the Russian Federation are considered. The modern Russian e-Commerce market still lags behind foreign ones in terms of the number of users and assortment, but it shows high annual growth rates. The article substantiates the point of view that the further development of e-Commerce is one of the key drivers of growth of all trade in the Russian Federation and the economy total. So, it is very important to assess not only the current state of the e-commerce market, but also to identify perspective trends in its development. E-commerce analysis of research if indicates that modern digital technologies can shape and control the way that a buyer goes from getting acquainted with a product to purchasing it. Digital technologies help to create new patterns of customer relationship. The article offers an overview of the main areas of use of digital technologies that are used in this field: Big Data and personalization, mobile Commerce, Blockchain technology, social networks. This overview can be useful to the scientific and business communities when conducting research in the field of digital economy, when building business plans and strategies taking into account the use of modern digital technologies in the development of the information society.
\end{abstract}

Keywords: digital technology, e-Commerce, digitalization, digital economy mobile commerce, personalization, blockchain technology, social networks, omnichannel business.

At the present stage of economic development, innovation and information, including digital technologies, are crucial for the effective functioning of enterprises and industries. Digitalization has a direct impact on business structures and government institutions, on the social and cultural sphere, on the development of society as a whole. [17] Digital technologies create a new value and allow leading enterprises and industries to achieve certain advantages in their field and to enter the international level. [14]

E-commerce, as a result of the initial dependence on the development of informational and digital technologies, is the most steadily developing sector of the economy of the Russian Federation. The active growth of the industry over recent years has had a serious impact on the economic development of traditional trade, interconnected industries and the state as a 
whole. [16] Thus, the problem of the state and prospects estimation for the development of the e-commerce industry, taking into account the usage of digital technologies, is one of the important and urgent problems of the Russian economy. [4]

At the moment, e-commerce organizations and enterprises are exploring new markets, studying the needs of customers, using the information necessary for this. They respond quickly to various changes in demand, reducing both financial and time costs, significantly increasing their competitiveness. Many offline enterprises and organizations today create online channels for sales, promotion and additional customer service. There are many factors limiting the development of electronic commerce (technical lack of training, an unworked legislative base, an insufficient number of specialists), however, seriousness and significance, as well as the growing potential of the electronic commerce market in our country, should be noted. [5] Thus, analysing segments of the Russian e-commerce market, it could be divided into three main categories: trade in goods (online retail), trade in services (transport tickets, hotel reservations, consumer services, etc.), content trading (video, music, books, software) and electronic banking, i.e, electronic payments. [10]

According to the expert's opinion, the fundamental features of the development of electronic commerce in Russia are:

- the increase of the number of industry participants;

- digitalization;

- building long-term strategies;

- large financial investments;

- strengthening both electronic and information security;

- improving the quality of service and expanding customer service;

- the increase of consumer loyalty to e-commerce [2]

Data Insight published a rating of the largest online stores in Russia according to the results of 2018. The rating was prepared with the support of the Russian Post. It included the hundred largest Russian stores in terms of online sales by the end of 2018. The basis of this list is a comprehensive methodology for rating building and data collection, including, amongst other things, a phased refinement of rating data from representatives of the stores themselves. The rating of online stores includes data on the volume of online sales and the number of orders. The three leaders include the largest online stores:

$1^{\text {st }}$ place - wildberries.ru, turnover was 111,200 million roubles, an increase of $74 \%$ from 2017

$2^{\text {nd }}$ place - citilink.ru, turnover was 73,200 million roubles, an increase from 2017 is $33 \%$

$3^{\text {rd }}$ place - mvideo.ru, turnover of 52,800 million roubles, an increase is $46 \%$. [8]

Thus, today the e-commerce market is an important component of the life of the population. Internet users order goods and services in real time, payment and delivery of products could also occur within the network. [3] The concept itself can be defined as follows: the e-commerce market is a kind of virtual space in which communication is carried out with the aim of mutually beneficial cooperation between various economic agents through the electronic systems usage. In addition to the obvious advantages of this market, such as time saving and usability, it is necessary to note such advantages of working in the field of e-commerce for entrepreneurs as the global Internet, that is, the lack of borders, lower transaction and marketing costs, which significantly increases competitiveness and has a stimulating effect on development of small and medium enterprises. There is an increase in the number of management objects (management of information, knowledge, creative and innovative potential, customer relationships, etc.). [18] [20]

This is especially true in connection with the development of the digitalization process and the formation of the economy 4.0. [13]. 
E-commerce enterprises are using digital technologies quite actively in comparison with enterprises of other industries in the Russian Federation, although not as actively as their foreign competitors do. This seems logical, since the emergence and functioning of ecommerce enterprises is due to the development and spread of the Internet, and, accordingly, information and digital technologies and tools. [9]

The main trends affecting the structure, dynamics and forms of development of electronic commerce in Russia largely coincide with the directions of development of global electronic commerce, however, they have some differences also. [12]

The development of electronic commerce in the Russian Federation is currently taking place in the following main areas, which are based on digital technologies:

- mobilization, in other words, the growth of mobile commerce - an increasing number of purchases are made using mobile devices, phones and tablets. Mobile applications also stimulate an increase in the number of customers, as they greatly simplify communication with companies offering goods and services. So, according to the results of a survey of PayPal and DataInsight in 2018,23.4\% of Russian users made purchases through the website of an online store using a smartphone, and $22.3 \%$ used mobile applications to order. The increase in mobile Internet users, today in Russia these are people from 15 to 40 years old, stimulates the development of mobile commerce. It should be noted that as a result, sales in the mobile commerce segment are growing much more actively than in e-commerce in general; [8]

- personalization and work with large volumes of data (Big Data) - collecting and analysing customer information opens up new possibilities: creating personalized product sets, which are based on purchase history, developing targeted offers and providing discounts to increase conversion, providing the visitor with the most convenient option for interacting with the Internet -store based on heat map statistics. Real-time monitoring allows online stores to organize and optimize the sales process. The usage of Big Data helps to deepen the personalization of stores, complicating the mechanism for setting the choice of goods, but this is a plus for the consumer, since he can adjust the choice to his own preferences, and the list of criteria for choosing products becomes larger, making the products presented at the end of the selection more suitable for individual buyer; [15]

- Blockchain is a distributed registry system, which based on mathematical algorithms and technologies of cryptography and security allows you to store any kind of information in data blocks in digital form. [7] The introduction of blockchain technology into electronic commerce will lead to the emergence of many free micro-markets. This will be facilitated by an increase in the number of e-commerce players: the threshold for entering the business will become lower, since digital tools based on distributed ledger technology for accounting, logistics, inventory management, budget planning and payroll significantly reduce operating costs. This technology can be applied to absolutely any type of data, and therefore blockchain is considered a revolutionary technology. The decentralized registry in which this data will be stored is almost impossible to crack. The essence of decentralization is that the data is stored on a huge number of separate computers on the network, and not on one centralized server, which is hacked and the data is stolen; [6]

- Socialization (Social Networking Services) - the usage of social networks for the purchase of various goods and services. Social networks are the universal environment for organizing electronic commerce, as they have a number of advantages: they include a wider and, at the same time, specific coverage of the target audience. A regular, traditional advertising company is much more expensive than advertising in social networks. In modern conditions, social networks exceed the popularity significantly of all traditional advertising media and the audience is constantly growing. Advertising in social networks is nonintrusive, non-aggressive and is recommendatory on the part of other users, friends, acquaintances. Advertising in social networks or the so-called targeted advertising is one of the most effective tools for goods and services promotion, which makes it possible to increase 
sales through a social network and improve communication with a client. It includes animated or text messages that users of the network see and that meet the set of criteria specified by the advertiser. This is an advertisement intended for a specific target audience, that is, it has the ability to address advertising messages only to those who may be of interest to them. Targeted advertising on social networks makes it possible to advertise a product without a website, use flexible settings for choosing the main target groups, and work with each group separately developing advertising messages for different audiences. A promising tool for working in social networks is the work to create and promote communities; [10] [11]

- omnichannel of e-commerce - is the use of all together or a certain number of channels in the process of working with a buyer. The receipt and storage of information makes it possible to further analyze this information and create an omnichannel service on the basis of it. The omnichannel functioning is possible in several versions - firstly, this is the offer of goods and services depending on the needs of the buyer, and secondly, the availability of goods from any device online and offline. Large producers of goods and services today use, at an average, nine communication channels. The ability to make a purchase anywhere - on the social network page or in the messenger is highly appreciated by modern consumers. [21]

All channels are interconnected and complement each other, thus forming a single system or platform that connects the seller and the buyer: email, social networks, messengers, voice communications, mobile applications, search queries and push notifications. [19]

It is necessary to emphasize the growing relationship between the digital technologies usage, working with databases and information software, high-tech equipment, on the one hand, and drawing up business plans, building a marketing strategy, developing financial models, analytical reports, on the other. A change in one of these components often leads to changes in the other components. This relationship becomes especially significant when long-term strategies are developed. Increasing the market share, moving towards improving the quality or lowering the cost of services while increasing the productivity of workers - are increasingly dependent on the types and quality of modern information and communication technologies in the enterprise. [1]

Based on the above, it should be concluded that the introduction of modern digital technologies in the field of electronic commerce gives enterprises undoubted advantages: this is an opportunity to optimize business processes and receive more necessary information, which means making more rational and informed decisions, improving communication with consumers and improve logistics, and what is most important - to compete successfully both on the Russian and international markets.

\section{References}

1. Baldin K.V. Information technologies in management: Textbook. for students of institutions of higher professional education / K.V. Baldin. M.: Publishing House "ACADEMIA", 2017.288 p.

2. Epifanov E.S., Atarov N.Z. The main development stages of electronic business // Questions of the regional economy, 2016. V. 28. No. 3. P. 106-110

3. E-Commerce Research in Russia http://www.datainsight.ru/ecommerce2018

4. Kovalev S.V. Innovative development management of socio-economic systems under uncertainty (risk) // Innovation Management. 2017. No3. P. 208-218

5. Kraponina J.E. The e-commerce market: global trends and Russian realities // Bulletin of the North Caucasus Humanitarian University. 2016. No3 (19). P. 30-36

6. William Mougayar, The Business Blockchain, translation from English, M.: EKSMO, 2018, p.224.

7. Pogrebinskaya E.A. Evaluation of the opportunity costs of organizing and manufacturing medical and healthcare services using blockchain technology // Eighth Czarnowski 
Readings. Proceedings of the VIII All-Russian Scientific Conference on the Organization of Production. Forum Modern Enterprise And The Future Of Russia. Moscow, December 7-8, 2018 - Moscow: REC “Controlling and Management Innovations”, BMSTU; Higher School of Engineering Business, 2019. P. 103-105.

8. Rating TOP-100 of the largest online stores in Russia https://www.top100.datainsight.ru

9. Rusyaeva D.O., Yadova N.E. Effective communications in electronic commerce // European Journal of Social Sciences, 2018, No. 7 (2). P. 41-48

10. Sedykh I.A. The Internet Commerce Market in the Russian Federation // HSE Reviews of Key Industries and Markets. "Center of Development Institute". [Electronic resource] - Access mode: https://dcenter.hse.ru. Access date - 10/18/2019

11. Yadova N.E. A model for evaluating the effectiveness of communications in electronic commerce: dissertation ... Ph.D. in Economics. 2019. p.158.

12. Yadova N.E. The current state of the global e-commerce market and the prospects for its development // Bulletin of Moscow State Regional University. Series: Economics. 2019. No. 2. P.116-125

13. De Reuver M., Sorenson C., Basole R.C. The digital platform: a research agenda // Journal of Information Technology.2018. Vol.33. No 2. P. 123-134

14. Eduardsen J. Internationalisation Through Digitalisation: the Impact of E-Commerce Usage on Internationalisation in Small- and Medium-Sized Firms / Ed. Van Tulder R., Verbeke A. and Piscitello L. International Business in the Information and Digital Age (Progress in International Business Research, Vol. 13), Emerald Publishing Limited, pp. 159-186.

15. Goerger S.R., Robert L. H. Impact of Technology on Operations Research Analysis // JSTOR.Vol. 49, No. 2. 2016. pp. 34-37. www.jstor.org/stable/24910192

16. Hagberg J., Sundstorm M., Egels-Zanden N. The digitalization of retailing: an exploratory framework // International Journal of retail and Distribution Management, Vol. 44 No. 7, pp. 694-712. https://doi.org/10.1108/IJRDM-09-2015-0140

17. Janow M. E., Mavroidis P. C. Digital Trade, E-Commerce, the WTO and Regional Frameworks //World Trade Review. 2019. T. 18. №. S1. P. S1-S7.

18. Kollmann T., Lomberg C., Peschl A. Web 1.0, Web 2.0, and Web 3.0: The development of e-business //Encyclopedia of e-commerce development, implementation, and management. IGI Global, 2016. -P. 1139-1148.

19. https://www.bain.com/insights/omnichannel-grocery-is-open-for-business-and-ready-togrow/

20. https://www.retail.ru/rbc/pressreleases/pervaya-sistema-tsifrovizatsiya-v-torgovle/

21. https://onlinelibrary.wiley.com/doi/abs/10.1111/poms.13146 